\title{
Grain carbon isotope composition is a marker for allocation and harvest index in wheat
}

Jean-Baptiste Domergue ${ }^{1}$, Cyril Abadie ${ }^{1}$, Julie Lalande ${ }^{2}$, Jean-Charles Deswarte ${ }^{3}$, Eric S. Ober $^{4}$, Valerie Laurent ${ }^{5}$, Celine Zimmerli ${ }^{6}$, Phlippe Lerebour ${ }^{7}$, Laure Duchalais ${ }^{8}$, Camille Bedard $^{9}$, Jeremy Derory ${ }^{10}$, Thierry Moittie ${ }^{11}$, Marlene Lamothe ${ }^{12}$, Katia Beauchene ${ }^{13}$, Anis Limami $^{14}$, and Guillaume Tcherkez ${ }^{15}$

${ }^{1}$ University of Angers

${ }^{2}$ IRHS

${ }^{3}$ Arvalis Institut du Vegetal

${ }^{4}$ NIAB

${ }^{5}$ Florimond-Deprez

${ }^{6}$ BASF France

${ }^{7}$ Unisigma

${ }^{8}$ RAGT $2 \mathrm{n}$

${ }^{9}$ Secobra

${ }^{10}$ Groupe Limagrain

${ }^{11}$ ASUR Plant Breeding

${ }^{12} \mathrm{CNRS}$

${ }^{13}$ Arvalis Experimental Research Station Boigneville

${ }^{14}$ University of Angers, (IRHS 1345) Institute of Research of Horticulture and Seeds

${ }^{15}$ Affiliation not available

November 10, 2021

\begin{abstract}
The natural 13C abundance ( $13 \mathrm{C}$ ) in plant leaves has been used for decades with great success in agronomy to monitor water use efficiency and select modern cultivars adapted to dry conditions. However, in wheat, breeding also implies looking for genotypes with high carbon allocation to spikes and grains, and thus with a high harvest index and/or low carbon losses via respiration. Finding isotope-based markers of optimal carbon partitioning to grains would be extremely useful since isotope analyses are inexpensive and can be performed routinely at high throughput. Here, we took advantage of a set of field trials made of more than 600 plots with several wheat cultivars and measured agronomic parameters as well as $\delta 13 \mathrm{C}$ values in leaves and grains. We find a linear relationship between the apparent isotope discrimination between leaves and grain (denoted as $\Delta \delta$ corr), and the respiration use efficiency-to-harvest index ratio. It means that overall, efficient carbon allocation to grains is associated with a small isotopic difference between leaves and grains. Our results show that 13C natural abundance in grains has some potential to help finding genotypes with better carbon allocation properties and assisting current wheat breeding technologies
\end{abstract}

\section{Hosted file}

MainText_PCE.pdf available at https://authorea.com/users/445349/articles/544896-grain-carbonisotope-composition-is-a-marker-for-allocation-and-harvest-index-in-wheat 